affection, or, at least, they were perfectly compatible with the supposition of such a condition, certainly favoured by other considerations, and then the organic mischief in the lungs and brain would be regarded in the light of local topical complications, which, in children, we should be prepared to expect, from the general activity of their functions, would be severe and quick in progress, as appears to have been the case here in the lungs; for purulent deposition had occurred in isolated spots, most likely at the terminations of the smaller bronchi. I am not very clear in my own mind about the cause of the emphysematous state of the lungs, but certainly the efforts of the respiratory muscles were occasionally very laborious, so much so as to remind one of the paroxysms which occur in spasmodic asthma; and it is not improbable but that, during some of these efforts, the air cells might become ruptured, and their contents diffused.

In connection with the present communication, I may state that, ever since I began $m y$ professional career in this isolated village, I have been again and again impressed with the tendency of a very great proportion of the diseases coming under treatment to become endemic; and the following instances can appear no more surprising to your readers than they did to myself, at the time of their occurrence :About the period of prevalence of the present epidemic, three adult persons consulted me about discharging, with great pain, blood and shreds of fibrin along with their urine; this was the chief ailment, and there was no appreciable constitutional disturbance. Again, in one week, four individuals applied to me on account of agonising headache, which in some was so threatening as to require depletion. In the course of last year three children were brought to me, within the same fortnight, suffering from jaundice without any very obvious cause. In the February of the same year two persons were much tormented with a constant amnoying tinnitus aurium, without any other complaint, and a third person, who has experienced, for at least two years, an unceasing ringing in the ears from, I suspect, an organic cerebral affection, told me that it was much aggravated about this time.

There is something so extraordinary in these occurrences, or, at least, the relation of such is so rare, that they are quite calculated to create a suspicion as to whether the observer really designs to impose upon one's credulity, or he is mistaken in the alleged facts; and, for these reasons, I could scarcely have prevailed with myself to give them a serious consideration, had I not been encouraged so to do by a perusal of the excellent paper in the "Transactions," previously alluded to ; for in this Dr. Shapter mentions peritonitis and hydrocephalus having assumed the endemic character, which is equally remarkable with the occurrence of ailments of lesser importance.

It is not sufficient to set them down as purely accidental concurrences, for the great probability is judging from the past, that I shall not see two cases of either hæmaturia or icterus happening contemporaneously for the next two years, nay, much longer, except from some occasional and plainly manifest cause. Why discased action should prefer to locate itself in a particular region of the body, at one period of the year, and at another, very little re. mote, select a totally different one, is a question perhaps not very easy of solution; but that there is a disposition of this kind often prevailing, I feel pretty confident, few practical and observing men will dispute. The circumstance strongly reminds me of a custom, which must surely be a remnant of the old astrological system of medicine, that prevails in some rural districts among the blacksmith farriers, of always consulting "Moore's Almanac," before they perform any operation, for they have an impression that the "signs," as laid down by Moore, indicate where the greatest pressure of blood exists for that period, so that if one of their patients should present with a tumour on the thigh requiring extirpation, and they find that the "sign" lodges there that day, they refuse to operate, lest the pressure of blood might prove too great for restraint. Now, without professing for a moment to allow my faith such unbounded scope, as a belief in this doctrine requires, it may be surely allowed to reflect upon the origin of the impression amongst them. In regard to the order of appearance of epidemics in this village there appears to have been some regularity, but as I am not fully satisfied of the accuracy of my information on this head, part of it being built on popular tradition, I shall waive for the present any further remarks, being firmly convinced that all imperfect and unfounded statements are not only useless, but worse, by perplexing and rendering more intricate a subject which, of all others, is universally acknowledged to be involved in the greatest mystery.

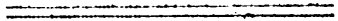

\section{FIVE CASES}

OF THE

\section{CROWING INSPIRATION OF CHILDREN,}

\section{WHICH OCCURRED IN THE SAME FAMILY.}

By Jonathan Toogood, Esq.,

Senior Surgeon to the Bridgwater Infirmary.

1817.-CASE I.-H. I., when about a year old, was suddenly seized, without any previous indisposition, with the following symptoms:-A slight crowing noise was first observed, a feeble distressing cry was uttered, followed by a sudden suspension of breathing and threatening of instant suffocation; the countenance became livid, the eyes starting from their sockets, frothy saliva was protruded from the mouth, the jaw fell, and he remained so long in this state that the bystanders thought he was dead. He was laid in a horizontal position and kept perfectly still, when, after a few minutes, a slight attempt at inspiration was made, which gradually improved, until his complete recovery was established. The contents of the bladder and rectum were evacuated during the attack; his countenance was very pale for a long time afterwards. During the next six months he had several slight attacks, which almost invariably commenced during comfortable easy sleep, and were preceded by an expression of pain in the countenance, and, although of short duration, were very distressing. After this time they ceased entirely, and he has grown up to manhood in the enjoyment of good health.

1821.-CASE II.-F. I., his brother, was attacked in the same manner when about six weeks old, and 
after repeated seizures, suddenly expired in one when fourteen weeks old.

1823.-CASE III.-O. I., another brother, had a similar attack when about a year and a half old, but less violent. These recurred occasionally until he was three years old, when they ceased. He has grown up to manhood in good health.

1826.-CASE IV.-A. I., another brother, began to have the same affection when about six months old, which continued until he completed his fourth year. During this period the attacks were sometimes so violent as to threaten instant death. They were occasioned by crying or passion, and once in consequence of a fall, which brought on so violent a seizure, that there appeared no probability of his recovery. He was kept perfectly still, with his head a little raised, and after two or three minutes he began to breathe again. After this he had slight attacks on crying or losing his breath, but never a serious one; the countenance always became livid, and respiration was suspended, but there was no convulsion, which invariably happened when the attack was severe.

October, 1829.-C CASE V.-M. A., a sister, a delicate child, born at eight months, was very well until six months, when she was seized exactly as her brothers had been, without any previous indisposition. These attacks recurred frequently until the end of May, after which time she had slight ones. Convulsions, lividity of the countenance, and evacuation of the contents of the rectum and bladder, always accompa nied the attacks. On one occasion she lay apparently dead, when the lungs were inflated, to which her recovery was attributed. Iu the month of June, when three quarters of a year old, the bones of the head, which had closed as firmly as usual at that period, except the anterior fontanelle, separated again, and the division of the sutures could be easily traced with the finger. After this she appeared to get much better, and the spine, which seemed inclined to bend before, became strong, and although she occasionally made a croupy noise, and had very slight attacks of lividity of the countenance, and temporary suspension of the breathing if she cried much, there was no severe symptom or convulsion. She continued pretty well until the 3rd of April following, and was a remarkably active, sprightly child, had eight teeth, and was then cutting the eye teeth. Whilst asleep in the garden she was suddenly attacked, as formerly, but soon recovered. This was supposed to arise from teething, and the gums were freely divided immediately. She now began to show symptoms of hooping-cough, and was often unwell, making a slight croupy noise, which, however, did not appear to hurt her, as she often laughed before it was scarcely over. Her nurse thought it a trick. She appeared to be going through the disease favourably, but on Tuesday night did not sleep as well as usual, from more frequent fits of coughing, and was irritable the next day, scratching those about her on the slightest cause. On the following day (Wednesday) she had another slight attack. Her bowels having been carefully attended to, and the cough having been more troublesome during the night, some ipecacuanha wine was given at eleven o'clock on Thursday morning, which operated well. At one, whilst lying in the nurse's lap, she had a most violent attack, and was, for some time, believed to be dead, but after pouring an ounce and a half of brandy and water down her throat, she slowly, and with great difficulty, recovered. This was followed by convulsion and long continued spasm of the muscles, so that the body was quite rigid and could not be bent, although kept for a considerable time in a warm bath. she appeared to suffer great pain for two hours, after which she became easier, and remained so till seven o'clock, when the spasms returned with equal violence, and recurred every two minutes, affecting the right side chiefly, until five o'clock the next morning. No relief was obtained from the application of leeches, warm bath, the warm water injection, or lancing the gums. About eight o'clock she screamed violently, but she was sensible and took nourishment several times. At ten the spasms returned, but with less violence, but they continued with little variation during the whole of Friday and until Sunday morning, when she appeared to get somewhat easier, and although she was less drawn, and the dreadful grinding of the teeth had subsided, there was still a constant frowning and knitting of the brows, denoting great pain. She appeared sensible during the greater part of Sunday, took food occasionally, and slept a good deal, but it was doubtful whether she saw distinctly; there was no squinting. On Sunday night she became affected with spasmodic twitchings of the muscles, and was sometimes harassed with cough. She had a repetition of her former attacks at four in the morning, and again at ten, from which, however, she soon recovered. Another fit recurred at twelve o'clock, whilst lying perfectly quiet, in which she expired.

The body was examined early on the following morning. It was not emaciated. Upon the removal of the pericranium, the skull-cap presented a natural appearance, the fontanelle not being perfectly closed by ossification. It required more than the usual degree of force to tear off the skull-cap from the dura mater, and when this was effected, it was found that a large portion of the membrane adhered to the right parietal bone. The veins were turgid with blood. Between the arachnoid membrane and the pia mater, a substance of a gelatinous nature, rather hazy or milky in colour, was diffused nearly over the whole surface. Some fluid escaped from the surface of the brain, but the quantity could not be ascertained. Upon cutting into the lateral ventricles, they were found to be distended with fluid, as was also the communication between these and the third ventricle, which, as well as the iter ad infundibulum, and the iter a tertio ad quartum ventriculum, was also distended with fluid. There was also much fluid at the base of the brain and in the fourth ventricle. The whole quantity amounted to about four ounces. The substance of the brain was softer than natural. The viscera of the chest and abdomen were healthy. No glandular affection could be detected in any of these cases.

A zoological society has just bcen formed at Berlin under the presidency of the distinguished Humboldt and a zoological garden is to be forthwith established at the south end of the park. The king has signified his approbation, by granting to the society all the animals, which were kept in the Island of Peacocks, near Berlin, and has authorised his treasurer to advance about 360,000 franes, without interest, repayable by ten equal yearly instalments.-Athenaum. 